\title{
Evaluation of Diamond Dressing Effect on Workpiece Surface Roughness by Way of Analysis of Variance
}

\author{
Frantisek HOLESOVSKY, Bingsuo PAN, Michael N. MORGAN, Andrej CZAN
}

\begin{abstract}
Wheel dressing is an important action in the grinding process. This paper reports on the comparative study of the performance of two types of diamond dresser tool measured in terms of ground surface roughness. For experiments were used two types of dressers, single point and multi-point diamond dresser. In addition to the dresser tool, the wheel dressing speed and dressing depth were taken into account as dressing variables. Cutting conditions were a constant; the results of dressing were observed for bearing steel $100 \mathrm{Cr} 6$. The experimental study was designed using an orthogonal array and experimental data were processed by the analysis-of-variance method (ANOVA). The results show that with a 95\% confidence, dressing with a multi-point diamond tool results in a smoother ground surface than with a single point diamond tool. As expected, wheel dressing speed and dressing depth also have significant effects on surface roughness. However, wheel dressing speed is much more influential than dressing depth.
\end{abstract}

Keywords: ANOVA; diamond dresser; dressing; grinding; surface roughness

\section{INTRODUCTION}

In grinding, the grinding wheel has to be dressed periodically to restore wheel form and cutting efficiency $[1,7]$. In diamond dressing, a number of parameters govern the process, including dressing depth, dressing lead/traverse rate, the type of dresser used and number of dressing passes $[2,3]$. Owing to the significant effects of dressing conditions on the shape and distribution of abrasive grits, which directly affect grinding quality $[4,6$, 8], grinding wheel wear, grinding force and grinding efficiency $[9,11,13]$ the importance of proper dressing of grinding wheels on precision machining cannot be emphasized too strongly.

This article describes an investigation into the performance of a single point diamond dresser and of a multi-point diamond dresser in cylindrical grinding of bearing steel [12]. Grinding wheel speed for dressing $\left(v_{\mathrm{s}}\right)$ and dressing depth $\left(a_{\mathrm{d}}\right)$ were also studied as independent variables. In grinding, which is commonly used as a finishing process, the quality of the generated surfaces is mainly evaluated by its roughness [4, 6, 10], thus the ground surface roughness was selected as the dependent variable. By means of analysis-of-variance (ANOVA) the performance of the two diamond dresser tools was compared with regard to ground surface roughness [5]. The percent contributions of grinding wheel speed and dressing depth to the total variation of surface roughness were evaluated in order to determine the significance of these two parameters for surface roughness.

Table 1 Design of dressing experiment and experimental data

\begin{tabular}{|c|c|c|c|c|c|c|c|}
\hline Test No. & $v_{\mathrm{s}}, \mathrm{m} / \mathrm{s}$ & $a_{\mathrm{d}}, \mathrm{mm}$ & dresser & $R a, \mu \mathrm{m}$ & $R z, \mu \mathrm{m}$ & $R_{\max }, \mu \mathrm{m}$ & $R t, \mu \mathrm{m}$ \\
\hline 1 & 10 & 0.02 & \multirow{9}{*}{ SP } & 0.849 & 5.38 & 6.75 & 6.88 \\
\hline 2 & 10 & 0.04 & & 0.770 & 5.32 & 8.06 & 8.39 \\
\hline 3 & 10 & 0.08 & & 0.929 & 6.14 & 7.99 & 8.37 \\
\hline 4 & 20 & 0.02 & & 0.625 & 4.27 & 5.35 & 5.48 \\
\hline 5 & 20 & 0.04 & & 0.562 & 4.02 & 4.79 & 5.20 \\
\hline 6 & 20 & 0.08 & & 0.850 & 5.30 & 6.41 & 6.70 \\
\hline 7 & 30 & 0.02 & & 0.385 & 2.98 & 3.59 & 3.76 \\
\hline 8 & 30 & 0.04 & & 0.370 & 2.90 & 3.53 & 3.67 \\
\hline 9 & 30 & 0.08 & & 0.538 & 3.93 & 4.70 & 4.85 \\
\hline 10 & 10 & 0.02 & \multirow{9}{*}{ MP } & 0.613 & 4.41 & 5.12 & 5.42 \\
\hline 11 & 10 & 0.04 & & 0.676 & 4.64 & 5.59 & 6.00 \\
\hline 12 & 10 & 0.08 & & 0.771 & 5.04 & 6.60 & 6.87 \\
\hline 13 & 20 & 0.02 & & 0.354 & 2.64 & 3.16 & 3.28 \\
\hline 14 & 20 & 0.04 & & 0.529 & 3.70 & 4.26 & 4.42 \\
\hline 15 & 20 & 0.08 & & 0.589 & 4.13 & 5.06 & 5.29 \\
\hline 16 & 30 & 0.02 & & 0.309 & 2.43 & 2.85 & 3.01 \\
\hline 17 & 30 & 0.04 & & 0.326 & 2.56 & 2.96 & 3.12 \\
\hline 18 & 30 & 0.08 & & 0.552 & 3.75 & 4.40 & 4.66 \\
\hline
\end{tabular}

\section{EXPERIMENTAL STUDY}

Three dressing parameters, namely grinding wheel speed for dressing $\left(v_{\mathrm{s}}\right)$, dressing depth $\left(a_{\mathrm{d}}\right)$ and type of dresser were chosen as the variables. Grinding wheel speed was set at the three levels: $10 \mathrm{~m} / \mathrm{s}, 20 \mathrm{~m} / \mathrm{s}$ and $30 \mathrm{~m} / \mathrm{s}$; dressing depth was set at the three levels: $0.02 \mathrm{~mm}, 0.04$ $\mathrm{mm}$ and $0.08 \mathrm{~mm}$. Two types of dressers were tested, single point diamond dresser (SP) and multi-point diamond dresser (MP). During dressing, the transverse rate of dresser was maintained at $1.0 \mathrm{~mm} / \mathrm{s}$ and the dresser was cooled with cutting fluid at flow rate of approximately 10 
1/min (cutting emulsion Robol 5\% - produce company Triga). The design of experiment methodology is detailed in Tab. 1, together with the recorded data.

Tests listed in Tab. 1 were conducted in a random order. In every dressing test, the wheel was firstly dressed with a constant dressing depth of $0.08 \mathrm{~mm}$ for one pass, and then dressed with the set dressing depth to enable study of the subsequent pass. For each dressing test, four cylindrical surface grinding tests were undertaken successively. All grinding tests were completed on a cylindrical grinding machine (TOS BU 16). A SG grinding wheel $(\varnothing 300 \times 32 \mathrm{~mm})$, cutting fluid and a bearing steel workpiece $(\varnothing 85 \times 20.55 \mathrm{~mm})$ of hardness of $62 \mathrm{HRc}$ were employed. Grinding parameters were: grinding wheel speed $=30 \mathrm{~m} / \mathrm{s}$, workpiece speed $=20 \mathrm{~m} / \mathrm{min}$, in feed speed $=0.26 \mathrm{~mm} / \mathrm{min}$. To determine the resulting roughness, for every grinding test three measurements were taken at three different sections across the thickness of the workpiece with a Hommel Tester T1000 profilometer, produced by Hommelwerke $\mathrm{GmbH}$. Hence each roughness value presented in Tab. 1 is the average of twelve measured roughness values. In each measurement, four surface parameters, $R a, R z, R_{\max }, R t$, were recorded. The scan distance was set at $4.8 \mathrm{~mm}$ and single sampling length at $0.8 \mathrm{~mm}$, as shown in Fig. 1 .

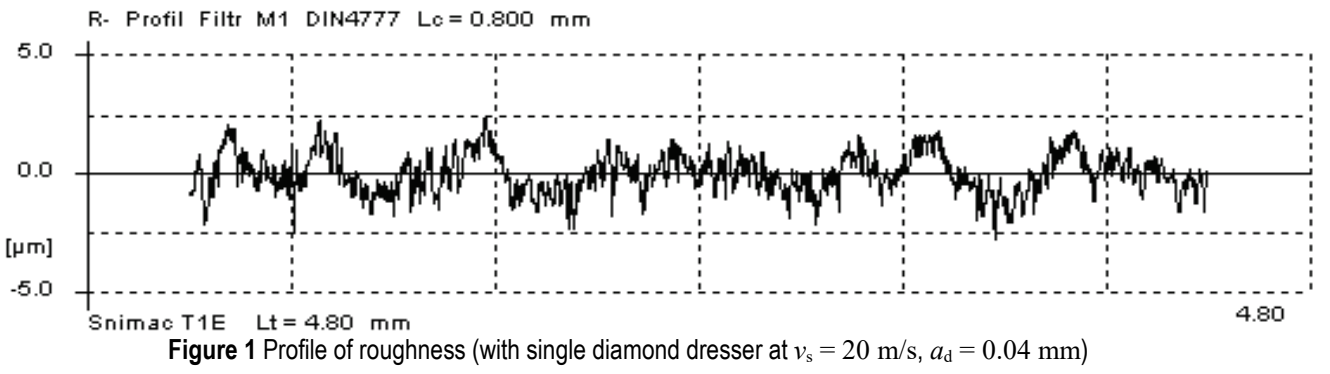

\section{EXPERIMENTAL RESULTS}

The experimental data in Tab. 1 were processed to obtain the relationship between ground surface roughness and dressing parameters. This relationship is presented graphically in Figs. 2, 3 and 4.

Fig. 2 compares the effect of single point diamond dressing on surface roughness with that of multi-point diamond dressing. In terms of all four measured surface parameters, the multi-point diamond dressing decreased their values by approximately $20 \%$ respectively, with those obtained in single point diamond dressing as a baseline. It indicates that multi-point diamond dressing can result in a smoother surface than single point diamond dressing.

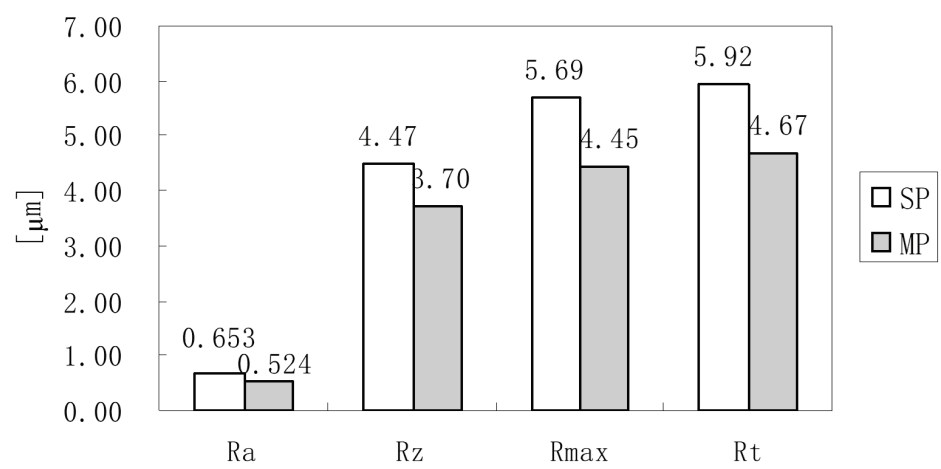

Figure 2 Comparison of effect of single point dressing on roughness with multi-point dressing

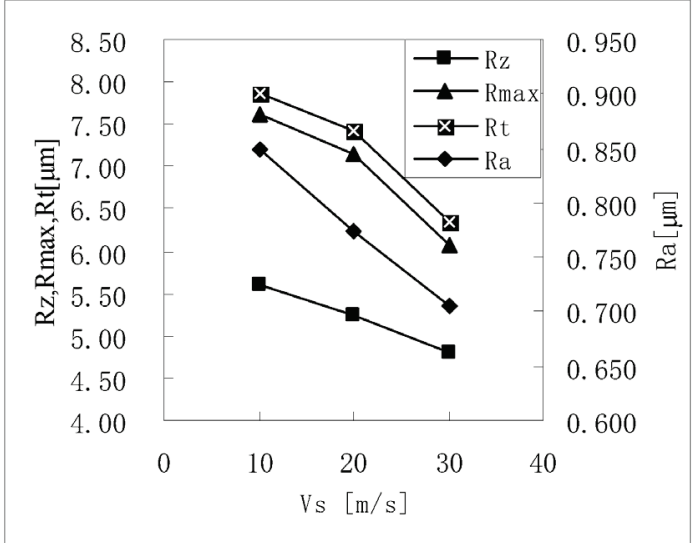

(a) in single point diamond dressing

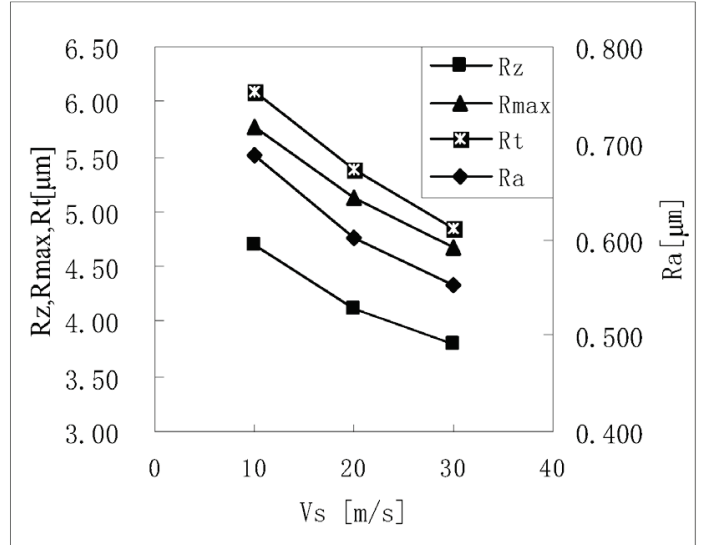

(b) in multi-point diamond dressing

Figure 3 Effect of wheel speed on surface roughness $\left(A_{\mathrm{d}}=0,04 \mathrm{~mm}\right)$ 


\section{STATISTICAL ANALYSIS OF RESULTS 4.1 Effect of Dresser Type}

The effect of diamond dresser type was evaluated by Multivariate Analysis of Variance (MANOVA), for which data is shown in Tab. 2 and Tab. 3. This analysis was used to test the equality of the mean roughness values resulting from single point diamond dressing to those resulting from multi-point diamond dressing. In the MANOVA table, the F-test $\mathrm{p}$-values for dresser, which are rather small, provide significant evidence that the average ground surface roughness for one type of dressing is different to the other when alpha is 0.05 . Given their averages $(R a=0.524 \mu \mathrm{m}$, $R t=4.67 \mu \mathrm{m}$ for multi-point dresser and $R a=0.653 \mu \mathrm{m}$, $R t=5.92 \mu \mathrm{m}$ for single point dresser). A further conclusion can be drawn with $95 \%$ confidence level that by using a multi-point diamond dresser smoother surface can be produced. The MANOVA results for $R z$ and $R_{\max }$ were similar to those of Rt.

The $p$-values for the interaction terms, dresser $* v_{\mathrm{s}}$ and dresser $* a_{\mathrm{d}}$, indicate that the strength of the effect of dresser type is dependent also on grinding wheel speed and dressing depth. To get an objective view of the impact of the dressing, it will affect the speed of the disc and the depth of dressing observed on two different types of dresser. However, the interaction between grinding wheel speed and dressing depth cannot be confirmed, owing to the large $p$-values.

Multivariate analysis of experimental data variance obtained in single point diamond dressing was shown in Tab. 4. According to the $F$-test $p$-values, it can be determined that both $v_{\mathrm{s}}$ and $a_{\mathrm{d}}$ are statistically significant

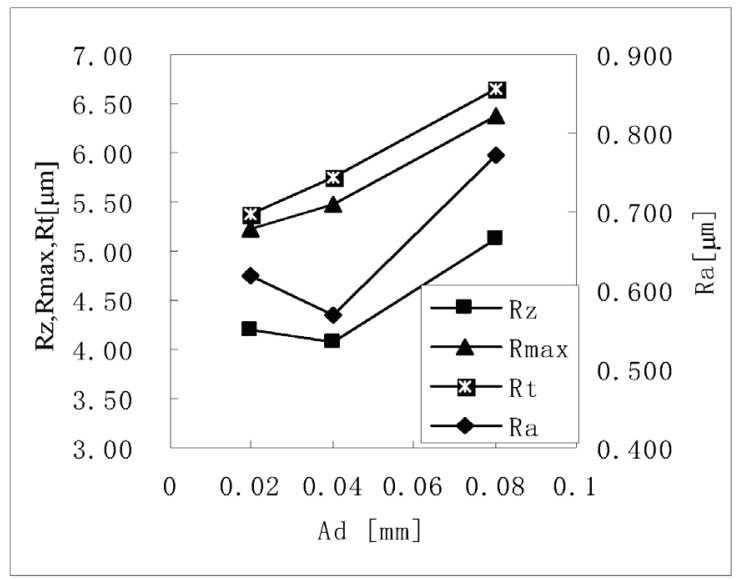

(a) in single point diamond dressing for $R a$ at confidence level alpha $=0.05$. Based on variance components estimates, $76.67 \%$ of the total variation in $\mathrm{Ra}$ was due to the differences between $v_{\mathrm{s}}$ levels, while $18.82 \%$ resulted from the differences between $a_{\mathrm{d}}$ levels. For $R t, v_{\mathrm{s}}$ is still a more significant factor, contributing a dominating percent, $83.40 \%$, to its variation. It is reasonable to conclude that in single point diamond dressing and for the conditions studied, grinding wheel speed has a much stronger influence on $R a$ than dressing depth and $R t$ is strongly influenced by grinding wheel speed.

Table 2 MANOVA table for $R a$ versus type of dresser, $v_{\mathrm{s}}$ and $a_{\mathrm{d}}$

\begin{tabular}{|l|c|c|c|c|c|}
\hline \multicolumn{1}{|c|}{ Source } & $D F$ & $S S$ & $M S$ & $F$ Ratio & $P$ \\
\hline dresser & 1 & 0.07463 & 0.07463 & 27.07 & 0.006 \\
$v_{\mathrm{s}}$ & 2 & 0.37750 & 0.18875 & 68.47 & 0.001 \\
$a_{\mathrm{d}}$ & 2 & 0.12214 & 0.06107 & 22.15 & 0.007 \\
dresser* $v_{\mathrm{s}}$ & 2 & 0.02014 & 0.01007 & 3.65 & 0.125 \\
dresser* $a_{\mathrm{d}}$ & 2 & 0.01423 & 0.00712 & 2.58 & 0.191 \\
$V_{\mathrm{s}} * a_{\mathrm{d}}$ & 4 & 0.00765 & 0.00191 & 0.69 & 0.634 \\
Error & 4 & 0.01103 & 0.00276 & & \\
Total & 17 & 0.62732 & & & \\
\hline
\end{tabular}

Table 3 MANOVA table for $R t$ versus type of dresser, $v_{\mathrm{s}}$ and $a_{\mathrm{d}}$

\begin{tabular}{|l|c|c|c|c|c|}
\hline \multicolumn{1}{|c|}{ Source } & $D F$ & $S S$ & $M S$ & $F$ Ratio & $P$ \\
\hline dresser & 1 & 7.0063 & 7.0063 & 38.92 & 0.003 \\
$v_{\mathrm{s}}$ & 2 & 30.1457 & 15.0729 & 83.73 & 0.001 \\
$a_{\mathrm{d}}$ & 2 & 6.8607 & 3.4304 & 19.06 & 0.009 \\
dresser* $v_{\mathrm{s}}$ & 2 & 1.3462 & 0.6731 & 3.74 & 0.121 \\
dresser* $a_{\mathrm{d}}$ & 2 & 0.1431 & 0.0716 & 0.40 & 0.696 \\
$V_{\mathrm{s}} * a_{\mathrm{d}}$ & 4 & 0.7110 & 0.1777 & 0.99 & 0.505 \\
Error & 4 & 0.7201 & 0.1800 & & \\
Total & 17 & 46.9331 & & & \\
\hline
\end{tabular}

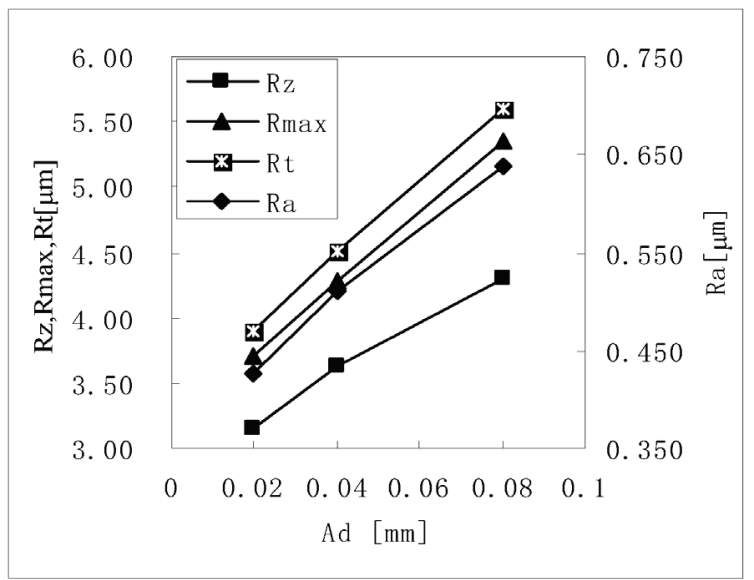

(b) in multi-point diamond dressing

Figure 4 Effect of dressing depth on surface roughness $\left(v_{\mathrm{s}}=30 \mathrm{~m} / \mathrm{s}\right)$
Tab. 5 is the ANOVA data for $R a$ and $R t$ obtained for multi-point diamond dressing. As the p-values for $v_{s}$ are rather small, there is significant evidence for $\mathrm{v}_{\mathrm{s}}$ main effects on $R a$ and $R t$ at alpha $=0.05$ level. It contributed $59.90 \%$ and $66.27 \%$ to the total variation of $R a$ and of $R t$, respectively. Likewise, the tests also indicate that factor $\mathrm{a}_{\mathrm{d}}$ has a significant effect on surface roughness, by contributing $29.71 \%$ to the total variation of $R a$ and $29.28 \%$ to the variation of $R t$. Hence $\mathrm{a}_{\mathrm{d}}$ was approximately half as influential as $v_{\mathrm{s}}$. Compared to its effect in single diamond dressing, there is evident improvement. Therefore, in multi-point diamond dressing, considerable attention should be paid to the choice of dressing depth while strictly controlling grinding wheel speed in order to obtain a desirable dressing result.

The variation in Error values imply that the experimental conditions were well controlled and the experimental data are reliable. 
Table 4 ANOVA result for single point diamond dressing

\begin{tabular}{|c|c|c|c|c|c|c|}
\hline \multicolumn{7}{|c|}{ Ra versus $v_{s}, a_{d}$} \\
\hline Source & $D F$ & $S S$ & $M S$ & $F$ Ratio & $P$ & pct. contribution \\
\hline$v_{\mathrm{s}}$ & 2 & 0.265520 & 0.132760 & 68.95 & 0.001 & $76.67 \%$ \\
\hline$a_{\mathrm{d}}$ & 2 & 0.068071 & 0.034035 & 17.68 & 0.010 & $18.82 \%$ \\
\hline Error & 4 & 0.007702 & 0.001925 & & & $4.51 \%$ \\
\hline Total & 8 & 0.341293 & & & & $100 \%$ \\
\hline \multicolumn{7}{|c|}{$R t$ versus $v_{\mathrm{s}}, a_{\mathrm{d}}$} \\
\hline Source & $D F$ & $S S$ & $M S$ & $F$ Ratio & $P$ & pct. contribution \\
\hline$v_{\mathrm{s}}$ & 2 & 21.5830 & 10.7915 & 39.23 & 0.002 & $83.40 \%$ \\
\hline$a_{\mathrm{d}}$ & 2 & 2.5350 & 1.2675 & 4.61 & 0.092 & $7.87 \%$ \\
\hline Error & 4 & 1.1003 & 0.2751 & & & $8.73 \%$ \\
\hline Total & 8 & 25.2184 & & & & $100 \%$ \\
\hline
\end{tabular}

Table 5 ANOVA result for multi-point diamond dressing

\begin{tabular}{|c|c|c|c|c|c|c|}
\hline \multicolumn{7}{|c|}{$R a$ versus $v_{\mathrm{s}}, a_{\mathrm{d}}$} \\
\hline Source & $D F$ & $S S$ & $M S$ & $F$ Ratio & $P$ & pct. contribution \\
\hline$v_{\mathrm{s}}$ & 2 & 0.132122 & 0.066061 & 24.07 & 0.006 & $59.90 \%$ \\
\hline$a_{\mathrm{d}}$ & 2 & 0.068298 & 0.034149 & 12.44 & 0.019 & $29.71 \%$ \\
\hline Error & 4 & 0.010976 & 0.002744 & & & $10.39 \%$ \\
\hline Total & 8 & 0.211396 & & & & $100 \%$ \\
\hline \multicolumn{7}{|c|}{$R t$ versus $v_{\mathrm{s}}, a_{\mathrm{d}}$} \\
\hline Source & $D F$ & $S S$ & $M S$ & F Ratio & $P$ & pct. contribution \\
\hline$v_{\mathrm{s}}$ & 2 & 9.9089 & 4.95444 & 59.92 & 0.001 & $66.27 \%$ \\
\hline$a_{\mathrm{d}}$ & 2 & 4.4688 & 2.23441 & 27.03 & 0.005 & $29.28 \%$ \\
\hline Error & 4 & 0.3307 & 0.08268 & & & $4.45 \%$ \\
\hline Total & 8 & 14.7084 & & & & $100 \%$ \\
\hline
\end{tabular}

\section{APPLICATION IN PRODUCTION}

The results were applied in optimizing the grinding of pin from steel 100Cr6. To achieve a good surface the multilevel feed of grinding wheel was used (Fig. 5). Feedrate was changed from $6.7 \mathrm{~mm} / \mathrm{min}$ to $1.5 \mathrm{~mm} / \mathrm{min}$ in the last step. Due to the use of abrasive grain Cubitron II the dressing depth was not changed, but three sizes of dressing speed were used in verifying test. For the dressing was used multi-point dresser. The peripheral speed of the grinding wheel was constant for all measuring $-45 \mathrm{~m} / \mathrm{s}$. During the optimization also the time of grinding was taken into account - time which was based on the initial state at the grinding, when the surface roughness $R a$ $=0.39 \mu \mathrm{m}$ was achieved.

Fig. 6 shows a high dependence of the surface quality on the longitudinal velocity of dresser, can simultaneously evaluate the effect of single degrees of feed rate of the tool in the working phase. It seems the dressing speed 50 $\mathrm{mm} / \mathrm{min}$ is the most appropriate at the gradually decreasing feed speed from the value 6.6 to $2.5 \mathrm{~mm} / \mathrm{min}$ (cycle A) - (Fig. 7). With this procedure, we achieve the repeated roughness $R a$ under $0.18 \mu \mathrm{m}$. on $\mathrm{CNC}$ grinding machine. Under graph, we can then track the individual average values of surface roughness $R a$ and $R z$.

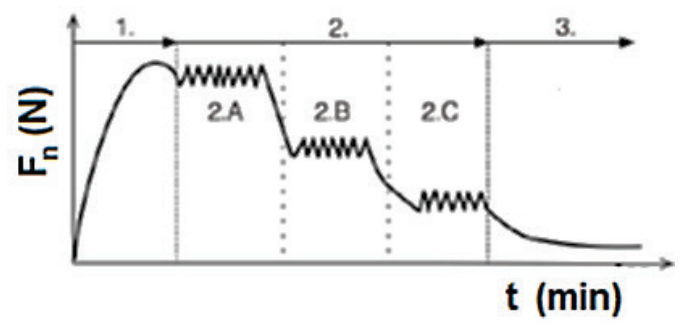

Figure 5 Grinding cycle, 2A - roughing, 2B - cleaning, 2C - finishing

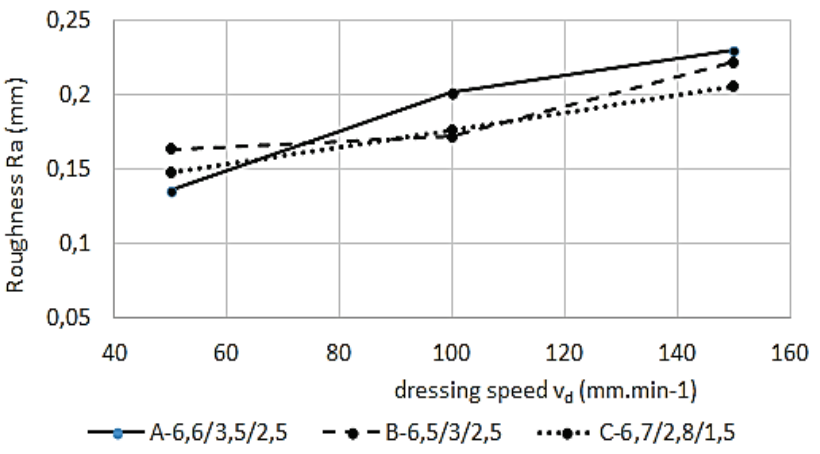

Figure 6 Dependence of surface roughness on the longitudinal velocity of dresser with various types of grinding cycle

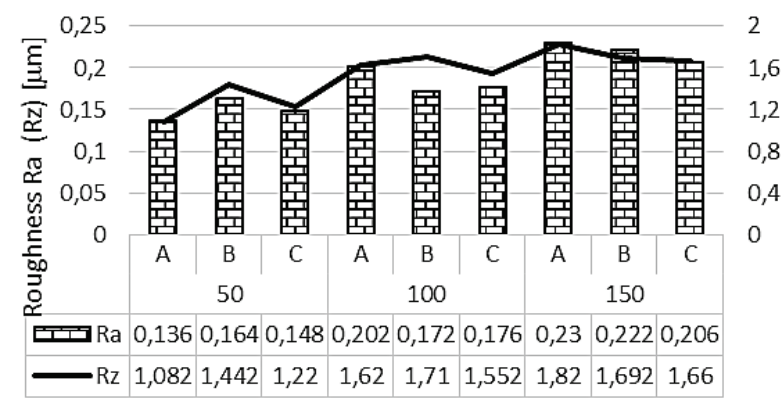

Figure 7 The dependence of the parameters of surface roughness and its numerical values on the type of cycle and the dressing speed

In said application at the using grinding wheel with grains of Cubitron II, this dependence is in force:

$$
R a=0,022 \cdot v_{\mathrm{d}}^{0,47}, \mu \mathrm{m}
$$

\section{CONCLUSION}

The conclusions drawn from this study are:

1) multi-point diamond dressing can result in a smoother 
ground surface than single point diamond dressing; to a certain degree, the effect of dresser type depends also on grinding wheel speed and dressing depth;

2) in single point diamond dressing, grinding wheel speed for dressing has a dominant effect on surface roughness in terms of $R a$ and $R t$, while dressing depth has only limited effect on $R a$ and no significant effect on $R t$;

3) in multi-point diamond dressing, both grinding wheel speed for dressing and dressing depth are statistically significant to surface roughness. However, grinding wheel speed is twice as effective as dressing depth;

4) the value of surface roughness can be determined using the mathematical relations:

for single point dresser $-R a=1,32 \cdot v_{\mathrm{s}}^{-0,18}, \mu \mathrm{m}$

for multi-point dresser $-R a=1,12 \cdot v_{\mathrm{s}}^{-0,21}, \mu \mathrm{m}$

the applicability of the relations has been verified by many experiments.

These values may provide the basis for further studies with differing abrasive and work material types.

\section{Acknowledgements}

This research was supported by the national grant GA CR 101/06/0508 - entitled "Research of surface properties with regard to possible impacts on the functionality of machine parts".

\section{REFERENCES}

[1] Chen, X. \& Rowe, W. B. (1996). Analysis and simulation of the grinding process. Part I: Generation of the grinding wheel surface. Int. J. Math. Tools Manufact., 36(8), 871882. https://doi.org/10.1016/0890-6955(96)00116-2

[2] Xue, L., Naghdy, F., \& Cook, C. (2002). Monitoring of wheel dressing operations for precision grinding. FIEEE International Conference on Industrial Technology, 2, 1296-1299.

[3] Bianchi, E. C., Vargas, V. L., Magagnin, T. C. et al. (2003). Transverse cylindrical grinding of a eutectic alloy. J. Braz. Soc. Mech. Sci. \& Eng., 25(1), 79-84. https://doi.org/10.1590/S1678-58782003000100011

[4] Fredj, B., Amamou, N., \& Rezgui, R. (2002). Ground surface roughness prediction based upon experimental design and neural network models. IEEE International Conference on Systems, Man and Cybernetics, Tunisia: IEEE, 752-756. https://doi.org/10.1109/ICSMC.2002.1176341

[5] Jurkovic, Z., Cukor, G., \& Andrejcak, I. (2010). Improving the surface roughness at longitudinal turning using the different optimization methods. Technical Gazette, 17(4), 397-402.

[6] Mochida, Y., Nishioka, T., Kubo, A., \& Tamaki, J. (2010). Evaluation of diamond dressers and estimation of grinding performance by dressing force measurement Int. J. of Abrasive Technology, 3(1), 37-50. https://doi.org/10.1504//JAT.2010.032461
[7] Transchel, R., Dold, C., Rabiey, M., \& Wegener, K. (2012). Relevance of laser touch-dressed diamond tools for the dressing performance of vitrified-bonded silicon carbide wheels. Int. J. of Abrasive Technology, 5(1), 48-61. https://doi.org/10.1504/IJAT.2012.046828

[8] Kuen-Ren, Ch. \& Hong-Tsu, Y. (2010). Modelling on dressing effects in chemical mechanical polishing with diamond dressers. Int. J. of Abrasive Technology, 3(1), 110. https://doi.org/10.1504/IJAT.2010.032458

[9] Malkin, S. (1989). Grinding Technology - Theory and applications of machining with abrasives. SME, Deaborn, Michigan.

[10] Marinescu, D. I., Rowe, W. B., Dimitrov, B., \& Inasaki, I. (2004). Tribology of abrasive machining processes. William Andrew, Inc. United States. https://doi.org/10.1115/1.1819313

[11] Marinescu, D. I., Hitchiner, M. et al. (2007) Handbook of Machining with Grinding Wheels. CRC Press, Taylor \& Francis Group, New York.

[12] Bilek, O., Hrdina, J., Lukovics, I., Pero, R., \& Samek, D. (2014). Improved shape of rotating grinding wheels for high speed grinding. Technical Gazette, 21(1), 63-68.

[13] Morgan, N. M. \& Jenkinson, D. I. (2006) Advances in Manufacturing Technology - XX. Proceeding of John Mores University, Liverpool.

\section{Contact information:}

Frantisek HOLESOVSKY, Prof.

Faculty of Technology and Production Managment,

University of J. E. Purkyně

Pasteurova 1, 40096 Ústí nad Labem, Czech Republic

E-mail: holesovsky@fvtm.ujep.cz

\section{Bingsuo PAN, PhD}

Department of Exploration Engineering,

China University of Geosciences,

No. 388 Lumo Road, 430074 Wuhan, P. R. China

E-mail: tungsten76@hotmail.com

\section{Michael N. MORGAN, Prof.}

Advanced Manufacturing Technology Research Laboratory,

Liverpool John Moores University,

3 Byrom St, Liverpool L3 3AF, UK

E-mail: M.N.Morgan@ljmu.ac.uk

Andrej CZAN, Prof

Department of Machining and Manufacturing Technology,

Faculty of Mechanical Engineering, University Žilina, Univerzitná 8215/1, 01026 Žilina, Slovak Republic

E-mail: andrej.czan@fstroj.uniza.sk 